\title{
Salbutamol: tablets, inhalational powder, or nebuliser?
}

\author{
K GRIMWOOD， J J JOHNSON-BARRETT， BRENT TAYLOR
}

\begin{abstract}
A study was carried out to ascertain the most effective method of giving salbutamol. Seventeen children with severe asthma received active salbutamol $(4 \mathrm{mg}$ via a nebuliser, $400 \mu \mathrm{g}$ as an inhalational powder, or a $4 \mathrm{mg}$ tablet) together with complementary placebos on a double-blind, triple-dummy randomly allocated basis. The bronchodilatation effect was assessed by measuring the peak expiratory flow rate.

The bronchodilatation effect was greatest when patients received nebulised salbutamol $(p<0.05)$ but lasted longest when they received the tablet $(p<0.0001)$; the onset of the effect was rapid with all forms of administration.

These results indicate that nebulised salbutamol gives the best relief in severe asthma; in less severe cases, however, a regimen combining the inhalational powder and tablets is sufficient and more convenient.
\end{abstract}

\section{Introduction}

Salbutamol has been used to treat asthma for about 15 years. Oral forms are generally believed to be less effective than inhaled forms, but few data exist to support this belief. A recent trial in asthmatic pre-school children showed an enhanced bronchodilator effect when nebulised salbutamol was given 90 minutes after an oral dose, but no direct comparisons were made. ${ }^{1}$

Metered-dose aerosols are not without problems; despite careful tuition they are used ineffectively by $14 \%$ of adults, ${ }^{2}$ the active drug or propellant may cause adverse effects, ${ }^{3-5}$ and the aerosols may be overused, especially in adolescence. ${ }^{6}$ Children aged under 5 years can seldom use a metered aerosol at all, and most of those under 8-10 years cannot use an aerosol effectively during an acute episode of wheezing. ?

Salbutamol delivered as a nebulised solution is effective in reducing bronchospasm in children aged over 20 months. ${ }^{8}$ Oral salbutamol and powdered salbutamol inhaled from a Rotahaler are effective in children aged over $3^{1}{ }^{9}$; salbutamol as an inhalational powder is at least as good as that given by metered aerosol in children aged over $7 .^{9}$ The bronchodilator effect of fenoterol in powder form is stronger and lasts longer than that of the same dose given by metered aerosol. ${ }^{10}$

In this study we compared three different modes of administration of salbutamol-namely, tablets, inhalational powder, and nebuliser.

\section{Subjects and methods}

We studied 17 children (seven boys and 10 girls) aged 4-12 (mean $7 \cdot 2$ ) years. The mean duration of asthmatic symptoms was 4.9 years (range one to 10 years). All had severe recurrent or chronic asthma (grade $\mathrm{C}$ or D) ${ }^{6}$ and were receiving continuous treatment with bronchodilators by mouth or inhalation, or both, and prophylactic antiasthma treatment.

Department of Paediatrics, Christchurch Clinical School of Medicine, Christchurch Hospital, Christchurch, New Zealand

K GRIMWOOD, $\mathrm{MB}, \mathrm{CHB}$, paediatric registrar

J J JOHNSON-BARRETT, trainee intern

BRENT TAYLOR, MRCP, FRACP, senior lecture
No subject received a sympathomimetic or theophylline within six hours of study. Sodium cromoglycate (13 subjects), beclomethasone dipropionate (two), and prednisone (three) were continued unchanged.

Respiratory function was assessed by peak expiratory flow rate using a Wright peak flow meter; the highest of three measurements was recorded before the drug was administered and thereafter at 15, 30, and 45 minutes and at one, one and a half, two, three, four, five, and six hours. Actual peak expiratory flow rates were converted to the percentage of the mean normal rate for height ${ }^{11}$ and the percentage improvement from the baseline value to permit intersubject comparison. Average individual variation in baseline values during the study was $8.0 \%$. Tuition and practice with placebo preparations were given before the trial.

At the same time on three days three or four days apart active salbutamol ( $4 \mathrm{mg}$ via a Hudson nebuliser or a $400 \mu \mathrm{g}$ capsule via a Rotahaler or a $4 \mathrm{mg}$ tablet) together with complementary placebos (physiological saline or glucose powder or glucose tablet) were given on a double-blind, triple-dummy randomly allocated basis.

\section{Results}

All subjects completed the first four hours of the trial, but two taking the tablet, three taking the powder, and one taking the nebulised form failed to complete the full six hours. One subject failed to reach six hours with each mode of administration. Peak expiratory flow rate improved in each child after treatment on each test day. The three preparations were well tolerated and did not produce the obvious side effects of palpitations, excitement, or tremor.

The table and figure show the results of the treatments. Two way

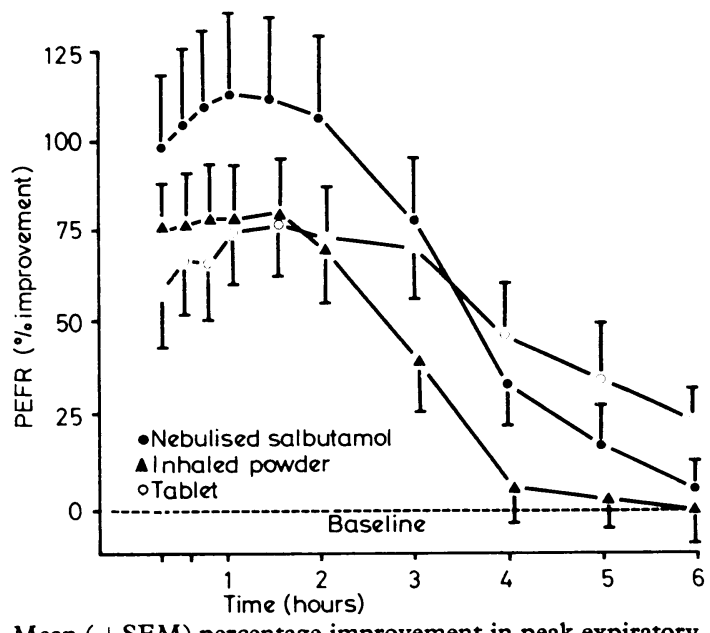

Mean ( + SEM) percentage improvement in peak expiratory flow rate (PEFR) with time in 17 severely asthmatic children given three forms of salbutamol.

Mean peak expiratory flow rate expressed as percentage of that expected and as percentage improvement over baseline values in 17 severely asthmatic children given salbutamol by mouth, Rotahaler, and nebuliser

\begin{tabular}{|c|c|c|c|c|c|}
\hline & \multicolumn{5}{|c|}{ Time after administration } \\
\hline & Baseline & $15 \mathrm{~min}$ & $45 \mathrm{~min}$ & $90 \mathrm{~min}$ & 4 hours \\
\hline $\begin{array}{l}\text { Tablet } \\
\text { Rotahaler } \\
\text { Nebuliser }\end{array}$ & $\begin{array}{l}58 \\
60 \\
59\end{array}$ & $\begin{array}{c}\% \text { of ex } \\
87 \\
98 \\
101 \\
\text { rovement }\end{array}$ & $\begin{array}{c}\text { ed value } \\
91 \\
98 \\
107 \\
\text { baseline v }\end{array}$ & $\begin{array}{r}97 \\
99 \\
107\end{array}$ & $\begin{array}{l}85 \\
63 \\
75\end{array}$ \\
\hline $\begin{array}{l}\text { Tablet } \\
\text { Rotahaler } \\
\text { Nebuliser }\end{array}$ & $\%$ & $\begin{array}{c}\text { rovement } \\
60 \\
73 \\
98\end{array}$ & $\begin{array}{c}\text { baseline } v \\
67 \\
78 \\
110\end{array}$ & $\begin{array}{r}78 \\
79 \\
111\end{array}$ & $\begin{array}{r}46 \\
7 \\
33\end{array}$ \\
\hline
\end{tabular}


analysis of variance with the three variables (treatments) over the four times shown in the table showed a significant difference in drug effect $(0.05>p>0.01)$, trial effect $(p<0.0001)$, and drug-trial interaction $(p<0.0001)$. The bronchodilatation effect was greater with nebulised salbutamol compared with the two other forms of administration but lasted longer with the oral treatment. Improvement in peak expiratory flow rate occurred rapidly after administration with all three methods. At 15 minutes the improvements in peak expiratory flow rate over baseline values achieved with the tablet and the powder were $61 \%$ and $75 \%$ respectively of the improvement achieved with the nebuliser.

\section{Discussion}

This study shows that the maximal bronchodilatation effect is obtained with nebulised salbutamol and confirms the effectiveness of this form of administration in asthmatic children. ${ }^{812}$ Unfortunately, nebulising systems are cumbersome and expensive and should probably be reserved for severely asthmatic patients.

The powder and tablet are easily administered and have a rapid onset of action. The powder is effective from at least the age of $3,{ }^{9}$ and inhaled forms reliably block exercise-induced bronchoconstriction..$^{13}$ Our study showed that the effect obtained with the powder was comparatively short, suggesting a need for frequent (three-hourly) administration. An increased dose might give a longer action. Powder forms are at least as $\operatorname{good}^{9}$ or better ${ }^{10}$ than metered-dose aerosols and avoid the risks, theoretical or otherwise, of using the aerosols.

The oral form, which is effective from at least the age of 3,1 had a surprisingly rapid onset of action, and its bronchodilatation effect was superior to that of the other forms of administration after four and six hours. It is less effective in exercise-induced bronchoconstriction, ${ }^{13} 14$ but its longer-lasting action has implications for prominent nocturnal symptoms. A combination of oral and inhaled forms has an additive effect on bronchodilatation with minimal increase in side effects ${ }^{15}$; such combination treatment in childhood needs further evaluation. All the children in this study had been taking oral or nebulised salbutamol regularly for months or years, which might explain the absence of troublesome side effects ${ }^{16}$ apparently prevalent in adults taking large doses ${ }^{15}$; children generally tolerate sympathomimetics well.

A regimen in which the powder is given during the day when the patient is active and the oral form given last thing at night or as baseline treatment may thus be optimal sympathomimetic treatment. Nebulised salbutamol should be reserved for patients with severe asthma.

We thank Mrs Catherine Reay for helping with this study; and Allen and Hanburys, division of Glaxo Laboratories (NZ) Ltd for providing placebo tablets and capsules.

\section{References}

${ }^{1}$ Groggins RC, Lenny W, Milner AD, Stokes GM. Efficacy of orally administered salbutamol and theophylline in pre-school children with asthma. Arch Dis Child 1980;55:204-6.

2 Patterson IC, Crompton SK. Use of pressurised aerosols by asthmatic patients. $B r$ Med $\mathcal{F} 1976 ; \mathrm{i}: 76-7$.

4 Anonymous. Wet or dry inhalers? Lancet 1978; i:79-80.

5 McLean AEM. Chlorofluorocarbons-in the can, in man and in the atmosphere. Br $\mathcal{F}$ Clin Pharmacol 1977;4:663-8.

6 Williams HE, Phelan PD. Asthma. In: Respiratory illness in children. Blackwell: Oxford, 1975:116-81.

${ }^{7}$ Landau LI. Nebulised bronchodilator therapy. Aust Paediatr 7 1978;14: 139-42.

${ }^{8}$ Lenny W, Milner AD. At what age do bronchodilators work ? Arch Dis Child 1978;53:532-5.

${ }^{9}$ Lenny W, Milner AD, Hiller EJ. Use of salbutamol powder in childhood asthma. Arch Dis Child 1978;53:958-60.

10 Chambers S, Dunbar J, Taylor B. Inhaled powder compared with aerosol administration of fenoterol in asthmatic children. Arch Dis Child 1980; $55: 73-4$

11 Cogswell JJ, Hull D, Milner AD, Norman AP, Taylor B. Lung function in childhood. III. Measurement of airflow resistance in healthy children. $\mathrm{Br} \mathcal{F}$ Dis Chest 1975;69:177-87.

12 Bacon CJ. Nebulised salbutamol in treatment of acute asthma in children. Lancet 1978; i:158.

13 Anderson SD, Rozea PJ, Dolton R, Lindsay DA. Inhaled and oral bronchodilator therapy in exercise-induced asthma. Aust $\mathrm{NZ} \mathcal{F} \mathrm{Med}$ $1975 ; 5$ (6):544-50.

${ }^{14}$ Bolme P, Eriksson M, Freyschuss W, Windbladh B. The effects of pharmacological treatment on pulmonary function in children with exercise induced asthma. Acta Paediatr Scand 1980;69:165-72.

15 Larrson S, Svedmyer N. Bronchodilating effect and side effects of beta adrenoceptor stimulants by different modes of administration (tablets, metered aerosol and combinations thereof). Am Rev Respir Dis 1977; $116: 861-9$.

${ }^{16}$ Larrson S, Svedmyer N, Keringer G. Lack of bronchial $\beta$-receptor resis tance in asthmatics during long term treatment with terbutaline. $\mathcal{F}$ Allergy Clin Immunol 1977;59:93-100.

(Accepted 31 October 1980)
3 Anonymous. Fluorocarbon aerosol propellants. Lancet 1975 ;i:1073-4.

\section{SHORT REPORTS}

\section{Hospital admissions for whooping cough in the Oxford Region, 1974-9}

The number of statutory notifications for whooping cough in the United Kingdom increased substantially during 1977-9 compared with the previous few years. There has been speculation $(a)$ about the extent to which this represented an increase in the proportion of cases notified as well as an increase in the incidence of the disease ${ }^{12}$; (b) about the extent to which other respiratory illnesses may have been misdiagnosed and notified erroneously as whooping cough ${ }^{34}$; and (c), because the increase in notification has not been paralleled by an increase in deaths from whooping cough, about whether any real increase in incidence has been one of relatively mild cases. We therefore studied statistics on hospital care for whooping cough in the Oxford Region.

\section{Methods and results}

Data on hospital discharges in the Oxford Region were obtained from Hospital Activity Analysis. This covers six of the seven health districts in the region (total population of districts covered about 2 million). The existence of linkable hospital data in the Oxford Region enabled us to identify a few patients who were readmitted to or transferred between hospitals, and to exclude their second and subsequent hospital episodes from the results. The diagnosis in Hospital Activity Analysis is that given at the time of the patients' discharge from hospital, but, for comparison with notifications, the data were analysed according to the dates of admission. Notification statistics for whooping cough were obtained for patients resident in the same six districts.

The figure shows the number of hospital admissions and statutory notifications in the six districts, plotted logarithmically, in each quarter of the year from 1974 to 1979 inclusive. The size of the population in the relevan age groups did not vary appreciably during the period and the results for age-specific admission rates were similar to those shown in the figure. The number of hospital admissions in the quarters centred on the 1978 peak was significantly higher than that in the quarters centred on the 1974 peak (Wilcoxon's rank sum test: $p<0.05$ ). Analysis by calculation of the correlation coefficient on the logarithmically transformed data showed a statistically significant association between the quarterly number of notifica- 